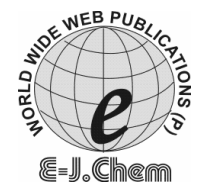

http://www.e-journals.net

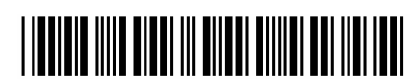

ISSN: 0973-4945; CODEN ECJHAO

E-Journal of Chemistry

2009, 6(2), 419-428

\title{
Eco-friendly Crosslinking Agent for Acid Functional Acrylic Resin
}

\author{
ARCHANA SHAH \\ Department of Chemical Sciences, \\ N.V.Patel College of Pure \& Applied Sciences, \\ Vallabh Vidyanagar-388120, Anand, Gujarat, India. \\ arc17973@yahoo.com
}

Received 3 August 2008; Accepted 10 October 2008

\begin{abstract}
Oil from J. multifida was extracted and it was first converted into $\mathrm{N}, \mathrm{N}$-bis(2-hydroxyethyl) Jatropha fatty amide (HEJFA). HEJFA has been synthesized by reaction between Jatropha oil and diethanol amine in presence of zinc oxide as a catalyst. The reaction is relatively rapid and proceeded to high yield at $200 \pm 5{ }^{\circ} \mathrm{C}$. The resulting HEJFA was used to formulate thermosetting coating compositions. Films were cured at ambient (air drying) and elevated (stove drying) temperatures using $N, N$-bis(2-hydroxyethyl) Jatropha fatty amide (HEJFA) as eco-friendly crosslinking agent for acrylic resin. The coating performance of the various compositions was tested by measurement of scratch hardness, impact strength and chemical resistance. The results show better performance of the HEJFA based compositions compared to butylated melamine formaldehyde (MF) based compositions.
\end{abstract}

Keywords: Jatropha oil, Acrylic resin, Eco-friendly Crosslinking Agent, Air drying, Stove drying, Coatings

\section{Introduction}

The uncontrolled emission of toxic gases, chemicals and effluents are causing irreparable damage to our environment and resulting into disturbing the ecological balance ${ }^{1}$. One of the major pollutants emitted by the usage of surface coatings is organic solvent used during their processing and application.

In the surface coating terminology such organic solvents are also called as Volatile Organic Compounds (VOC's). The increasing legislative restrictions on VOC emmision awareness among the surface coatings users force the technologists to develop the 
eco-friendly methods of surface coatings which are safer in production, storage and applications. These include the use of eco-friendly curing agent for coatings derived from vegetable oils which have been directly used to obtain films for paints and coatings.

Since the oils themselves cannot meet the desired film properties, a number of ways for oil modification have been proposed ${ }^{2,3}$ viz. introduction of functional groups like ester ${ }^{4}$, amide $^{5}$, oxirane ${ }^{6}$, urethane ${ }^{7}$, ester-amide ${ }^{8}$ etc. The synthesis of low molecular weight polymers like alkyds, polyepoxies, polyurethane and polyesteramide was carried out by the incorporation of such functional groups in oils ${ }^{9-12}$. These polymers hold considerable scope of application in the field of paints and coatings ${ }^{7,8,12-15}$. The presence of repeating units of ester $(-\mathrm{COOR})$ and amide $(-\mathrm{NCOR})$ in the polymeric chain of oil based polyesteramide (PEA), improves the ease of application, thermal stability, resistance against chemicals and water as well as causes faster drying and enhanced hardness over normal alkyds ${ }^{12-13}$. A number of PEAs have been developed by the reaction of fatty amides of oil of different seeds (e.g., castor $^{16}$, dehydrated castor ${ }^{17}$, pilu fat ${ }^{17}$, argemone ${ }^{18}$, linseed ${ }^{19}$, etc.) with dicarboxylic acids/anhydrides.

It has also been observed that these PEAs take shorter time $(10 \mathrm{~min})$ for curing at elevated temperature (at and above $160^{\circ} \mathrm{C}$ ) whereas considerably longer time (12-20 days) for room temperature curing ${ }^{8,18-19}$.

Thermosetting acrylic resins (TSA) are increasingly used in variety of industrial surface coating applications. Since they are designed to react chemically after application, TSA can have lower molecular weights and can be applied at higher solids, enabling the formulation of low VOC systems. Among the important types of cross-linking agents for hydroxyl functional resins, isocyanates (or blocked isocyanates) are used in formulation of acrylic urethane systems and alkylated amino resins. Carboxylic functional resins are invariably cured by glycidyl type cross-linking agents. Apart from the demanding requirements for wide range of applications, the increasing concern for environmental protection and toxicity hazards dictate the choice of the cross-linking agents such as the one which is described in the present paper. The traditional cross-linking agents are hazardous due to their toxicity and/or they produce toxic volatiles, such as formaldehyde during curing.

$\beta$-Hydroxyalkyl amide type cross-linking agents for carboxylic functional polymers have attracted the attention of many researchers in the present years ${ }^{20-22}$, particularly because of their low polluting potential.

The present communication deals with the synthesis of a novel crosslinking agent $v i z, N, N$-bis (2-hydroxyethyl) Jatropha fatty amide (HEJFA) derived from Jatropha (Pongamia pinnata) oil, which has been employed as a crosslinking agent for acid functional acrylic copolymer resin (AAR). For commercial applications low $\mathrm{Tg}$ copolymers are employed so as to avoid the problem of brittleness which may be incurred upon reaction. In our work, we employed higher $\mathrm{Tg}$ acrylic copolymer prepared with higher percentage of maleic anhydride and consequently with a higher acid number. The cross-linking agent acts as flexibilizing agent, which results in the lowering of $\mathrm{Tg}$ of our copolymer and consequently the resulting resin was brought in the sphere of acceptable useful surface coating ${ }^{22}$.

The various baked and ambient temperature cured film properties of the compositions having varying amounts of cross-linking agent have been studied. The compositions based on butylated melamine formaldehyde (MF) as cross-linking resin have been studied as reference ${ }^{22}$. 


\section{Experimental}

Jatropha oil was kindly supplied by SPRERI. The other chemicals such as acrylic monomer (methyl methacrylate), maleic anhydride, diethanolamine, zinc oxide, methanol, xylene, acetone and potassium hydroxide were of laboratory reagent grade. Butylated melamine formaldehyde (MF) was supplied by M/s Synthetics and Polymers Industries, Amdavad (Code M-310) and was used without any modification. The coatings were applied on mild steel panels and tinned panels as specified in the Indian Standard Specification ${ }^{23}$ to cast films having dry film thickness of approximately 30 microns. Mechanical properties of the film, such as flexibility and scratch hardness, have been determined as per Indian Standard Specification $^{23}$. The chemical resistance properties ${ }^{24}$ viz., acid and alkali resistance of the films were studied by immersion of coated panels in two percent by wt. of solution of $\mathrm{HCl}$ and $\mathrm{NaOH}$ respectively.

Synthesis of N,N-bis (2-hydroxyethyl) Jatropha fatty amide (HEJFA) and carboxylic acid functional acrylic resin $(A A R)$

HEJFA and AAR (copolymer of maleic anhydride and methyl methacrylate) were synthesized as per reported method ${ }^{22}$. The characteristics of HEJFA and AAR are shown in Tables 1 and 2 respectively. The HEJFA and AAR were duly characterized by IR spectra and shown in Figures 2 and 3 respectively.

Table 1. Characteristics of HEJFA.

\begin{tabular}{clc}
\hline S. No. & \multicolumn{1}{c}{ Properties } & Values \\
\hline 1 & Acid Value $(\mathrm{mg}$ of $\mathrm{KOH}), \mathrm{g}$ & 5.00 \\
2 & Viscosity at $25^{\mathrm{O}} \mathrm{C}$ (Poise) & 5.0 \\
3 & Specific Gravity & 0.92 \\
4 & Colour (gardner) & 13 \\
\hline
\end{tabular}

HEJFA is soluble in diethyl ether, petroleum ether and in lower alcohols.

Table 2. Characteristics of AAR (MA-MMA Copolymer).

\begin{tabular}{|c|c|c|c|c|c|c|c|}
\hline \multicolumn{4}{|c|}{ Feed Composition } & \multirow{3}{*}{$\begin{array}{l}\text { Yield, } \\
\text { g }\end{array}$} & \multirow{3}{*}{$\begin{array}{l}\text { Acid value } \\
\text { (mg of } \mathrm{KOH} / \mathrm{g} \text { of } \\
\text { copolymer) }\end{array}$} & \multirow{2}{*}{\multicolumn{2}{|c|}{$\begin{array}{c}\text { Copolymer } \\
\text { composition, moles }\end{array}$}} \\
\hline & & & & & & & \\
\hline moles & $\mathrm{g}$ & moles & g & & & $\overline{\mathrm{MA}}$ & MMA \\
\hline 0.306 & 30 & 0.70 & 70 & 75 & 115.6 & 0.076 & 0.675 \\
\hline
\end{tabular}

\section{Coating compositions}

Coating compositions having varying ratios of AAR/HEJFA have been prepared using xylene/acetone $(95 / 5 \% \mathrm{v} / \mathrm{v})$ as solvent. The corresponding reference compositions using MF resins have been prepared using xylene/butanol $(90 / 10 \% \mathrm{v} / \mathrm{v})$ as solvent. All the compositions were thinned to $50 \%$ by weight of non-volatile matter.

\section{Preparation of coating compositions of AAR and HEJFA}

The different compositions of AAR and HEJFA prepared for coating applications are shown in Table 3. The compositions have been applied on mild steel panels and tinned panels. The coated panels were baked in oven at $180{ }^{\circ} \mathrm{C}$ for $30 \mathrm{~min}$. The baked panels were kept for seven days and then different mechanical and chemical resistance tests were conducted. The same compositions were also air-dried after application on panels and were 
tested after seven days. The results obtained have been reported in Tables 4 and 5. Various compositions of AAR and MF resins have also been prepared and cured at $180{ }^{\circ} \mathrm{C}$ for $30 \mathrm{~min}$. These results also have been reported in Tables 4 and 5 . The proposed scheme for the crosslinking reaction between AAR and HEJFA is presented in Figure 1.

Table 3. Coating compositions of Copolymer and HEJFA.

\begin{tabular}{ccccccc}
\hline S. No. & $\begin{array}{c}\text { Composition } \\
\text { Code }\end{array}$ & AAR & HEJFA & Solvent & $\begin{array}{c}\text { AAR: } \\
\text { HEJFA }\end{array}$ & $\begin{array}{c}\text { AAR: } \\
\text { HEJFA }\end{array}$ \\
\hline 1 & 1 & 5.0 & 5.0 & 10.0 & $1: 1$ & $1: 0.577$ \\
2 & 2 & 6.0 & 3.0 & 9.0 & $2: 1$ & $1: 0.288$ \\
3 & 3 & 6.0 & 2.0 & 8.0 & $3: 1$ & $1: 0.192$ \\
\hline
\end{tabular}

Table 4. Air-Dried Film Properties of Various Compositions

\begin{tabular}{lcccc}
\hline \multicolumn{1}{c}{ Properties } & \multicolumn{3}{c}{ HEJFA : AAR } \\
\cline { 2 - 5 } & & $1: 1$ & $1: 2$ & $1: 3$ \\
\hline Scratch, g Passes & 800 & 1000 & 1200 \\
Impact Passes & $\mathrm{R}^{*}$ & 100 & 75 & 75 \\
(lb. inch) & $\mathrm{D}^{*}$ & 125 & 100 & 75 \\
Flexibility 1/8” & Pass & Pass & Pass \\
Acid Resistance (72 h) & F,B & C & C \\
Alkali Resistance & 5 days & 4 days & 3 days \\
(Ruptured) Days/ h. & & & \\
Xylene Resistance (72 h) & A & A & A \\
Water (7 days) blistering & F,C & F,D & F,Ds \\
\hline
\end{tabular}

$A=$ Not affected $B=$ Slight Swelling \& Slight blistering $C=$ Swelling \& blistering $D=$ Severe Swelling $\&$ blistering $E=$ Loss of adhesion $F=$ Loss of gloss $R^{*}=$ Reverse $D^{*}=$ Direct

Note: The values in impact resistance are arrived by multiplying wt. of indentor in lbs. $(6.25 \mathrm{lbs}$. with maximum height in inches from where indentor fails without any visible damage to the films.

Table 5. Baked Film Properties of Various Compositions.

\begin{tabular}{|c|c|c|c|c|c|c|c|}
\hline \multirow{3}{*}{ Properties } & & \multicolumn{6}{|c|}{ AAR, MA-MMA 30:70 wt./wt copolymer } \\
\hline & & \multicolumn{3}{|c|}{ HEJFA : AAR } & \multicolumn{3}{|c|}{ MF : AAR } \\
\hline & & $1: 1$ & $1: 2$ & $1: 3$ & $1: 1$ & $1: 2$ & $1: 3$ \\
\hline Scratch, g Passes & & 1800 & 2000 & 2400 & 800 & 1000 & 1400 \\
\hline Impact Passes & $\mathrm{R}^{*}$ & 225 & 200 & 200 & 25 & 25 & 25 \\
\hline (lb. inch) & $D^{*}$ & 250 & 225 & 225 & 25 & 25 & 25 \\
\hline Flexibility $1 / 8 "$ & & Pass & Pass & Pass & Fail & Fail & Fail \\
\hline Acid Resistance (72 h) & & $\mathrm{F}, \mathrm{A}$ & B & B & B & $\mathrm{C}$ & $\mathrm{C}$ \\
\hline $\begin{array}{l}\text { Alkali Resistance } \\
\text { (Ruptured) Days/ h. }\end{array}$ & & 5 days & 5 days & 3 days & $5 \mathrm{~h}$ & $4 \mathrm{~h}$ & $3.5 \mathrm{~h}$ \\
\hline Xylene Resistance (72 h) & & A & A & A & A & A & A \\
\hline Water (7 days) blistering & & 5 days & 5 days & 5 days & $\mathrm{B}$ & $\mathrm{B}$ & $\mathrm{C}$ \\
\hline
\end{tabular}

$A=$ Not affected $B=$ Slight Swelling \& Slight blistering $C=$ Swelling \& blistering $D=$ Severe Swelling $\&$ blistering $E=$ Loss of adhesion $F=$ Loss of gloss $R^{*}=$ Reverse $D^{*}=$ Direct

Note: The values in impact resistance are arrived by multiplying wt. of indentor in lbs. (6.25 lbs.) with maximum height in inches from where indentor fails without any visible damage to the films. 
(a)

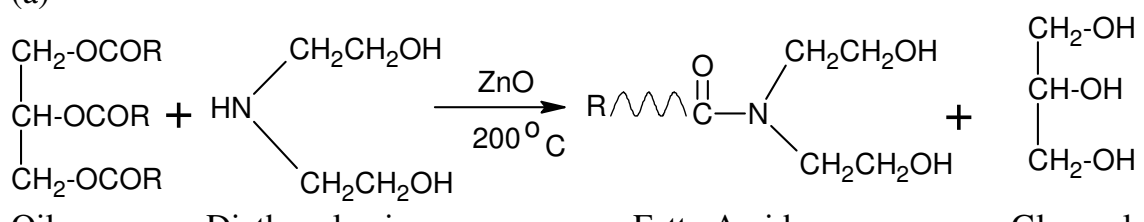
Oil Diethanolamine

Fatty Amide

Glycerol

(b)<smiles>[3H]CCCCC(CCCCCC(CC)C(=O)O)C(=O)O</smiles>
Copolymer
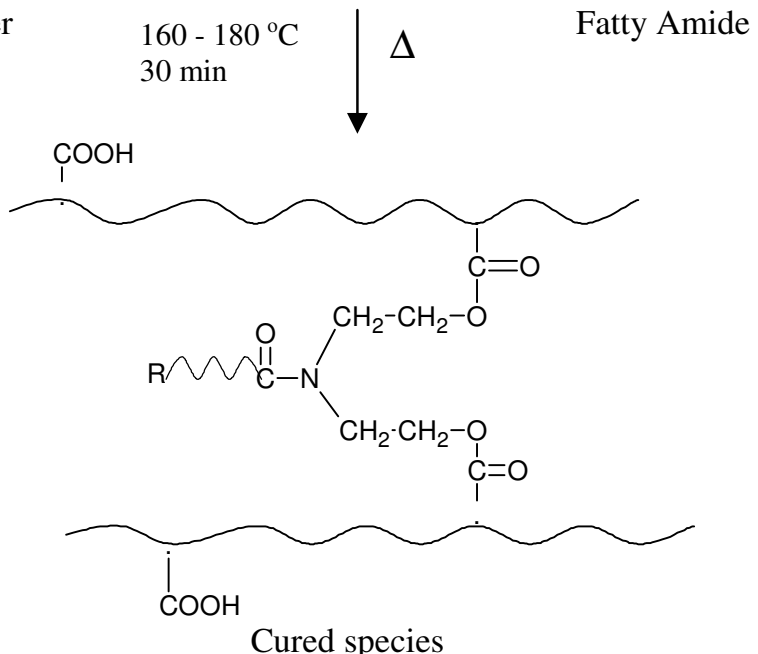

Figure 1. (a)Reaction scheme for preparing fatty amide; (b) Proposed scheme for crosslinking reaction between copolymer and fatty amide

\section{Results and Discussion}

The relative ease of uncatalysed esterification of carboxylic acids with $\beta$-hydroxyalkyl amides has been well documented in the literature ${ }^{20,25}$. In the present study the facile reaction has been extended to the cross-linking of carboxylic functional acrylic resins. In the selection of the alkyl group of the cross-linking agent, long chain fatty acids derived from Jatropha oil have been employed to confer hydrocarbon stability to the compound. Maleic anhydride, used as a functional monomer in AAR study is known to impart brittleness to the cured polymer films, resulting in poor impact resistance ${ }^{26}$. However, the incorporation of long chain fatty acid $\left(\mathrm{C}_{18}\right)$ moieties in the cross-linking agent is thought to serve as a flexibilizer and would improve mechanical properties of the film.

In order to find out the optimum temperature of cross-linking between AAR and HEJFA, a representative coating composition was subjected to various oven temperatures $\left(150-210{ }^{\circ} \mathrm{C}\right)$ for constant time period $(30 \mathrm{~min})$. The resulting thermosetting films were observed and the temperature giving best results, $180{ }^{\circ} \mathrm{C}$, was considered for further baking of the film. All the baked film properties have been, studied by baking the film at $180^{\circ} \mathrm{C}$ for $30 \mathrm{~min}$ 


\section{Spectral analysis of HEJFA and AAR}

The IR spectrum of HEJFA is shown in the Figure 2. The structure of HEJFA was confirmed by the following absorption band]. A broad band at $3350-3400 \mathrm{~cm}^{-1}$ may be due to free $-\mathrm{OH}$ group .A strong absorption in the region of $2850-2900 \mathrm{~cm}^{-1}$ is due to $\mathrm{C}-\mathrm{H}$ stretching. The presence of a strong band at $1739 \mathrm{~cm}^{-1}$ is due to the amide carbonyl. Strong absorption bands at $1633 \mathrm{~cm}^{-1}$ and $1463 \mathrm{~cm}^{-1}$ can be attributed respectively to a $3^{0}$ amide and C-H bending. A very strong absorption band at $1055 \mathrm{~cm}^{-1}$ is thought to be arising out of $\mathrm{C}-\mathrm{O}$ stretching and C-O bending of primary alcohol .A strong absorption band at $722 \mathrm{~cm}^{-1}$ and a weak absorption band at $938 \mathrm{~cm}^{-1}$ can be attributed to $\mathrm{C}-\mathrm{H}$ bending arising from polymethylene groups respectively which are present in the fatty acid moity.

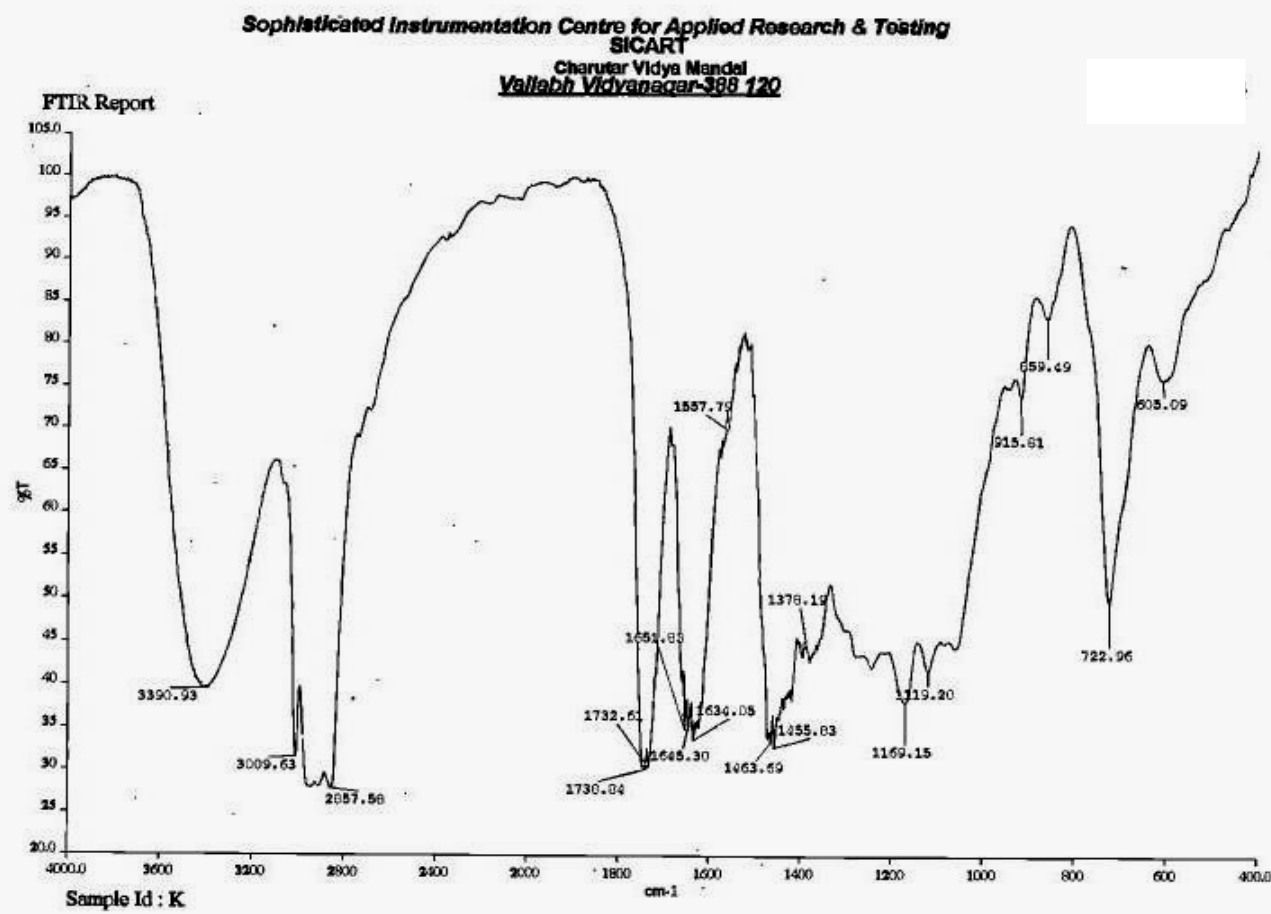

Figure 2. IR spectrum of HEJFA.

IR spectrum of AAR is shown in Figure 3. The presence of the carboxylic acid group is confirmed by a strong absorption band at $2958 \mathrm{~cm}^{-1}$. This confirms the inclusion of maleic anhydride in the copolymer. A strong band at $1736 \mathrm{~cm}^{-1}$ can be attributed to the ester group of the acrylic monomer.

\section{Film properties}

The films of the various HEJFA-based compositions have been subjected both to air-drying as well as baking at $180{ }^{\circ} \mathrm{C}$ for $30 \mathrm{~min}$. The MF based compositions were also baked at $180{ }^{\circ} \mathrm{C}$ for $30 \mathrm{~min}$. The mechanical and chemical resistance properties of these films are reported in Table 4 and 5 . 


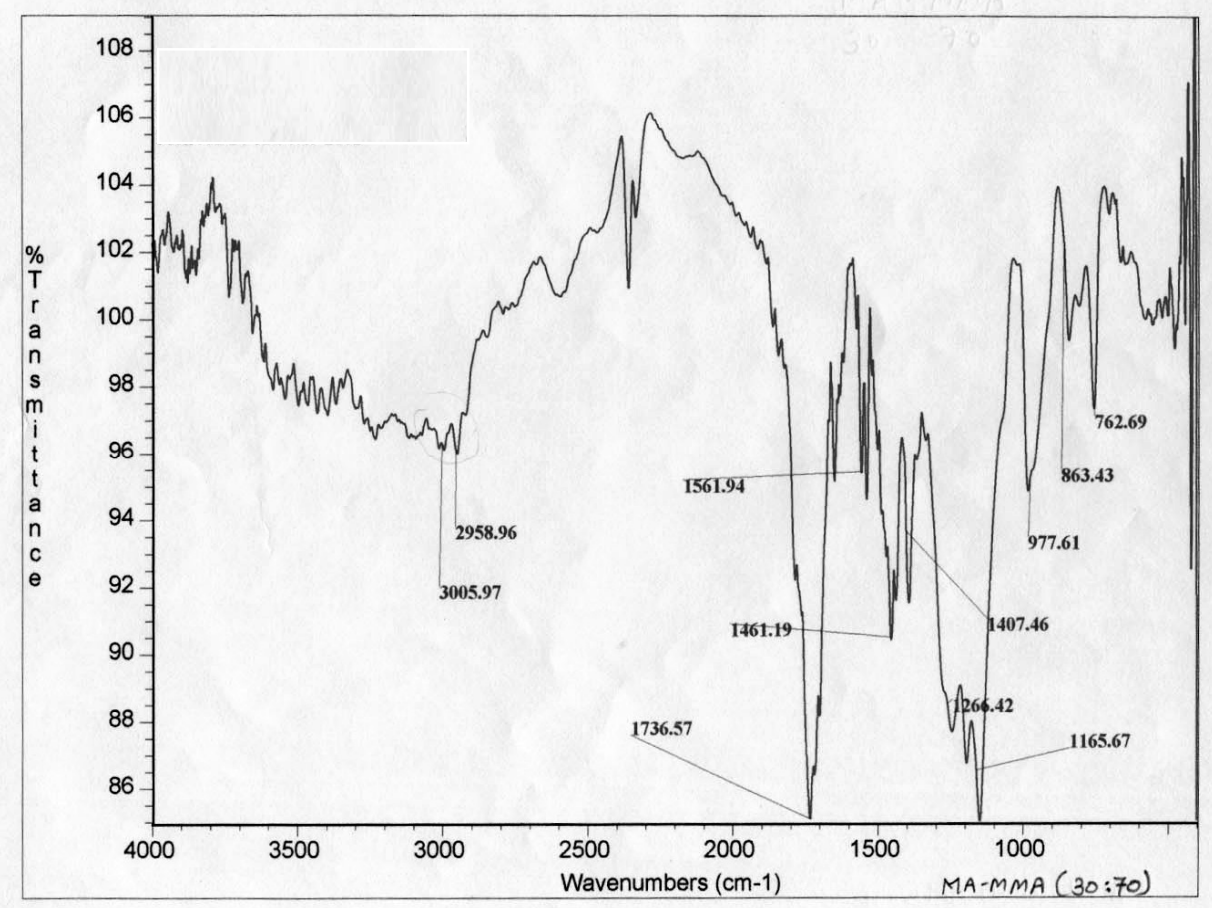

Figure 3. IR spectrum of AAR (MA-MMA (30: $70 \mathrm{wt} / \mathrm{wt}$ ) copolymer).

It is quite obvious that practically no cross-linking would take place under air-drying conditions since esterification reaction responsible for cross-linking requires either elevated temperature or presence of acid catalyst. In the present work, for examining the reactivity of HEJFA, both air-dried and baked films have been studied and compared.

The comparison of mechanical properties of the films of various compositions (Table 4 and 5) reveals that, in general, the air-dried films have poorer scratch hardness and impact resistance than their baked counterparts.

The scratch hardness properties of the film, in general, improve with increase in the film complexity resulting from higher degree of cross-link density. The impact resistance property reflects the film strength which improves the film hardness up to certain optimum value beyond which it reaches a stage of embrittlement resulting into reduced impact resistance. The significantly higher values of both scratch hardness and impact resistance of the baked films as compared to their air-dried counterparts (Table 4 and 5) clearly indicate that significant degree of cross-linking in baked films takes place.

A comparison of the mechanical properties of the films of various compositions provides interesting observations (Table 4 and 5).

The ratio of AAR/HEJFA has a controlling effect on the mechanical properties of both air-dried and baked films. The scratch hardness of both air-dried and baked films decreases while impact resistance improves with increase in HEJFA content of the composition.

A comparison of mechanical properties of backed films based on HEJFA and MF reveals that the scratch hardness and impact resistance properties of HEJFA based compositions are far superior to their MF counterparts. The extremely poor performance 
properties of MF based films can primarily be ascribed to the brittleness of the parent copolymer. Since MF is known to further bring about cross-linking and embrittlement during curing, it detracts the films from these mechanical properties.

In case of HEJFA based compositions, the presence of a nonpolar fatty acid moiety in HEJFA is thought to bring about the plasticizing effect in the films. With the increasing HEJFA content, therefore, the scratch hardness decreases. Similarly, the improvement in impact resistance of the films with increase in HEJFA content might be due to improved film toughness resulting out of reduced brittleness of the copolymer (AAR).

All the test panels pass the flexibility (1/8") test. The flexibility test was carried out according to IS method ${ }^{23}$. The compositions were applied on the tinned mild steel panels and cured as mentioned earlier to have the dry film thickness of about 30 microns. Mandrels having specified rod diameters were used for carrying out flexibility tests. For the determination of flexibility, a panel was inserted between the hinges and the rod of specified diameter, in such a way that the coated side remains outwards from the direction of bending. The hinge is closed evenly, without jerking in about one second bending the panel through $180^{\circ}$. The coating was examined immediately after bending and before removing it from the hinge for the evidence of cracking and loss of adhesion. The tests were performed by two different rod sizes viz. $1 / 4$ " and $1 / 8$ " rod diameter.

\section{Chemical and solvent resistance properties}

Table 3 and 4 present the chemical and solvent resistance properties of air-dried and baked films of various compositions. In general, the air-dried films are found to be markedly inferior to their baked counterparts. This can be attributed to significantly lower degree of cross-linking in air-dried films. The extremely poor alkali resistance of air-dried films is clearly indicative of the presence of significant number of free carboxylic acid groups originally present in the acrylic copolymer. Baked films, on the other hand, show very high degree of alkali resistance, indicating the absence of any significant number of free carboxylic acid groups some of which would have been cross-linked during baking. Compared to baked films, the relatively poor resistance of air-dried films for acid, xylene and water can also be accounted by the insignificant degree of cross-linking of former as compared to the latter.

A comparison of chemical resistance properties of both air-dried and baked films as a function of HEJFA content in their composition provides interesting observations.

In baked films, the alkali resistance property of the films improves with increase in HEJFA content of the composition. This might be due to reduction in the presence of free carboxylic groups due to esterification reaction (cross-linking reaction) during baking. However, no appreciable difference in time for rupture of air-dried film in alkali has been observed for the different compositions.

A slight lowering in time for rupture of film with increasing HEJFA content might be due to the ease of diffusion of alkali in the films due to their increase in softness.

Acid resistance of both air-dried and baked films are found to improve with increasing HEJFA content which might be due to increase in cross-linking density of the film.

Resistance to xylene and water to both the air-dried and baked film was similar to that observed for acid-resistance. The increasing resistance with increase in HEJFA content can be attributed to their higher degree of cross-linking in the film. 
Comparison of baked film properties of HEJFA and MF based compositions reveals that most of the chemical and solvent resistance properties are comparable except the alkali resistance properties. HEJFA based compositions are found to be significantly superior to their MF counterparts. Further, improvement in alkali resistance is found with increase in HEJFA content. This can be attributed to the higher degree of cross-linking in HEJFA based composition due to higher functionality of HEJFA. Increasing HEJFA content would lead to esterification of more free carboxylic acid groups of the copolymer and hence will improve alkali resistance of the cured films.

\section{Conclusion}

The results of the present study reveal that $N, N$-bis (2-hydroxyethyl) Jatropha fatty amide derived form Jatropha oil can be used successfully as a cross-linking agent in baking type coating compositions for the acid functional acrylic resins. The study indicates that the mechanical and the chemical properties of the films are dependent on HEJFA content of the composition and an optimum AAR/HEJFA ratio can be selected to obtain balanced film properties. A comparison of HEJFA with MF as a cross-linking agent for ssAAR reveals that HEJFA is much superior to MF in terms of chemical and mechanical film properties for the compositions studied. Further, since unlike MF, HEJFA does not produce any toxic volatiles during curing and hence is environmentally friendly.

\section{Acknowledgement}

The author wish to express his gratitude to the Executive Director, Sophisticated Instrumentation Centre for Applied Research and Testing (SICART), Vallabh Vidyanagar for providing necessary facilities for testing of the samples and Dr. R.A.Raval, Sarvoday Kelavani Samaj, Yogidham, Kalawad Road, Gujarat for his valuable guidance throughout the work.

\section{References}

1. Sukla M C, Paint India, 1999, Vol.XLIX, 37.

2. Gultekin M, Beker U, Guner F S, Erciyea A T and Yagci Y, Macromol Mater Eng., 2000, 283, 15.

3. Guner F S, Erciyes A T, Kabasakal O S and Yagci Y, New aspects on the modification of triglyseride oils, In: S G Pandalai (Ed.), Recent Research Developments in Oil Chemistry. Transworld Research Network., 1998, 31.

4. Can E, Kusefoglu S and Wool R P, J Appl Polym Sci., 2002, 83, 972.

5. Saunders K J, Organic Polymer Chemistry, $2^{\text {nd }}$ Ed., Chapman \& Hall, New York, 1981, 207.

.6. Chen J, Soucek M D, Simonsick W J and Celikay R W, Polymer, 2002, 43, 5379.

.7. Ahmad S, Ashraf S M, Sharmin E, Zafar F and Hasnat A, Prog Cryst Growth Charact Mater., 2002, 45, 83.

8. Ahmad S, Ashraf S M, Naqvi F, Yadav S and Hasnat A, Prog Org Coat., 2003, 47, 95.

9. Rokicki G, Lukasik L, Florjanczyk Z and Zukowska G, J Macromol Sci Pure Appl Chem., 1996, A33(4), 509.

10. Patel P, Shah T and Suthar B, J Polym Mater., 1989, 6, 193.

11. Trevino A S and Trumbo D L, Prog Org Coat., 2002, 44, 49.

12. Gast L E, Schneider W J and Cowan J C, J Am Oil Chem Soc., 1966, 43, 418.

13. Economy J, J Macromol Sci Chem., 1984, A 21, 1705.

14. Zafar F, Sharmin E, Ashraf S M and Ahmad S, J Appl Polym Sci., 2004, 92(4), 2538. 
15. Ahmad S, Naqvi F, Verma K L and Yadav S, J Appl Polym Sci., 1999, 72, 1679.

16. Raval D A, Roy T K and Mannari V M, J Sci Indian Res., 1996, 55, 263.

17. Roy T K, Mannari V M and Raval D A, J Sci Indian Res., 1997, 56, 159.

18. Mannari V M and Raval D A, Res and Ind., 1995, 40, 38.

19. Zafar F, Sharmin E, Ashraf S M and Ahmad S, Prog Org Coat., 2004, 51, 250-256.

20. Lomax J and Swift G, J Coating Tech., 1978, 50, 643.

21. Mercurio A, Proc $16^{\text {th }}$ Int Conf Org Coat Sci Tech, Athens, Greece, 1990, 235.

22. Raval D A, Patel V M and Parikh D, Chem Eng World, 2004, 39, 122.

23. Methods of Sampling and Testing for Varnishes and Lacquers (First revision, 1981), Bureau of Indian Standards, New Delhi: IS,, 1996.

24. Lambourne R, Paint and Surface Coatings, Theory and Practice, Ellis Horwood Ltd., Chichester,ch.16, 1981, 605.

25. Schneider W J, McManis G E, Swain E W and Gast J E, J Paint Tech., 1970, 43, 493.

26. Bridson J A Plastic Materials, $5^{\text {th }}$ Ed., Butterworth-Heinemann Ltd., Oxford, Ch., 26, 1989, 712. 


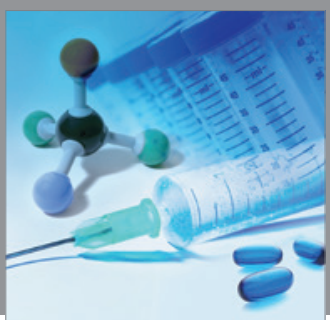

International Journal of

Medicinal Chemistry

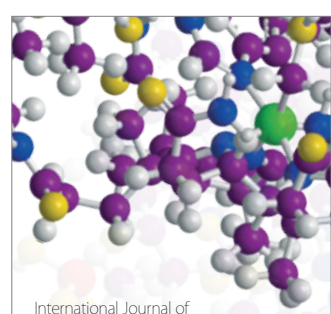

Carbohydrate Chemistry

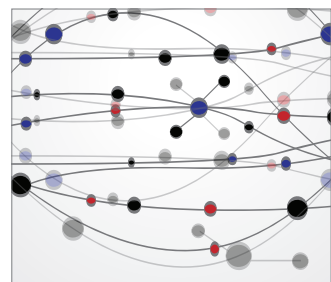

The Scientific World Journal
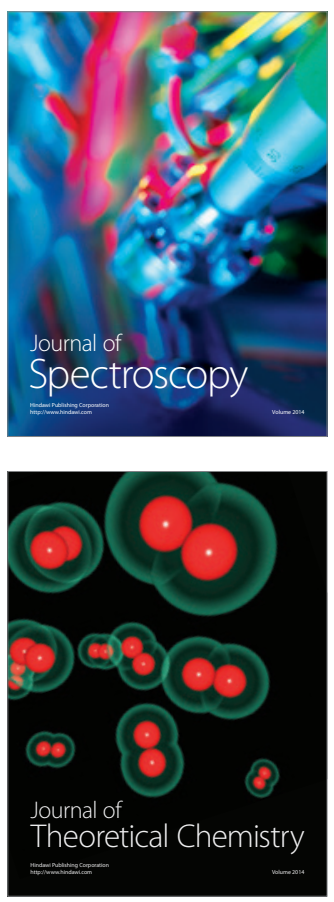
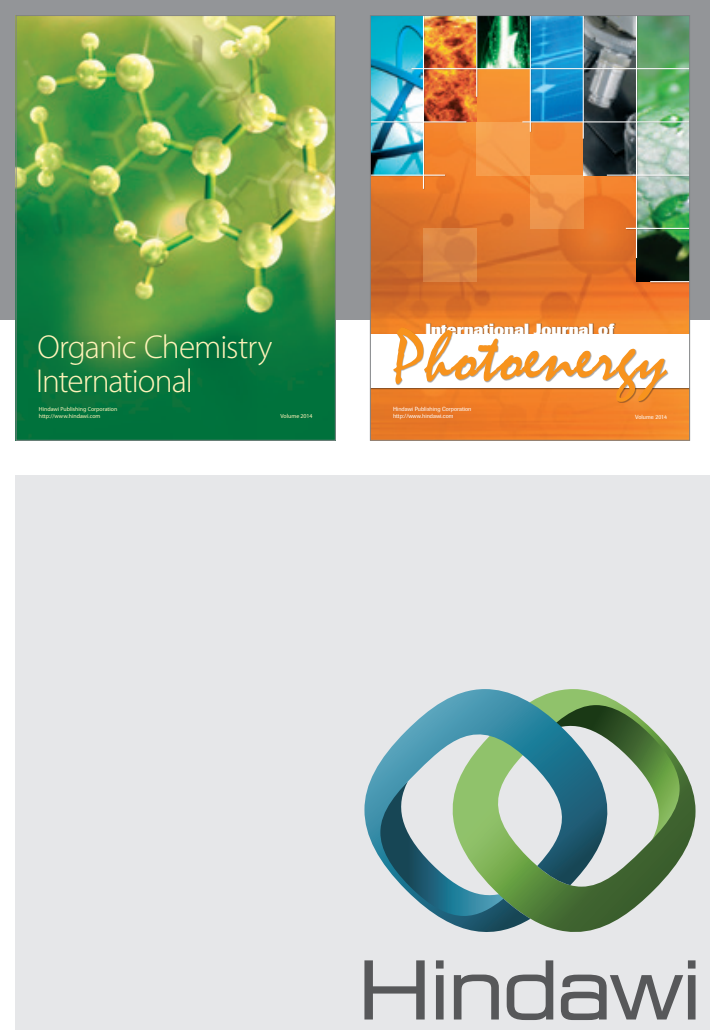

Submit your manuscripts at

http://www.hindawi.com
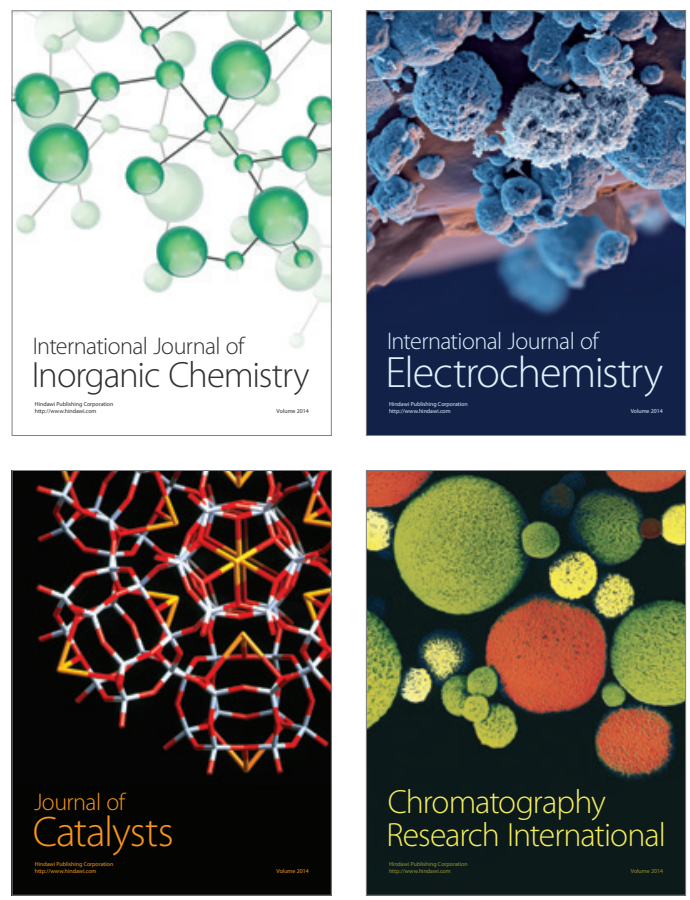
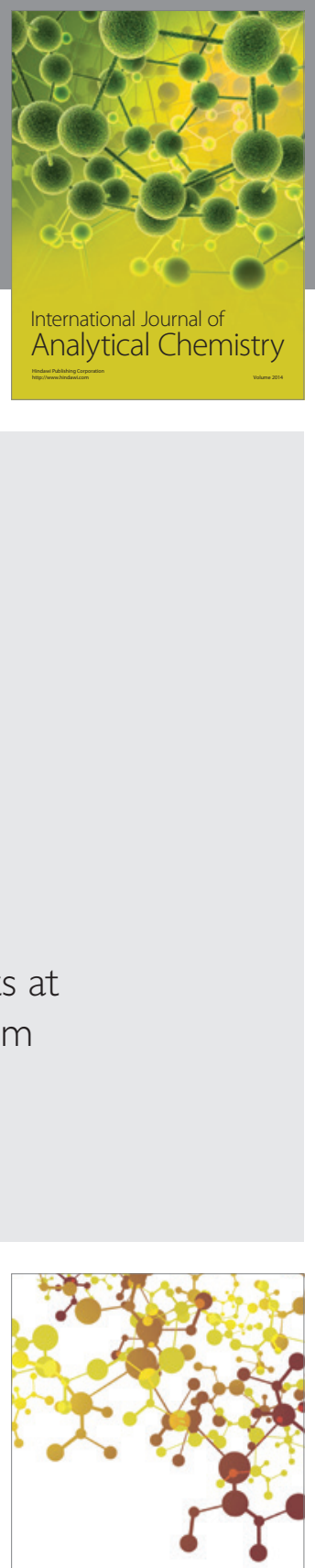

Journal of

Applied Chemistry
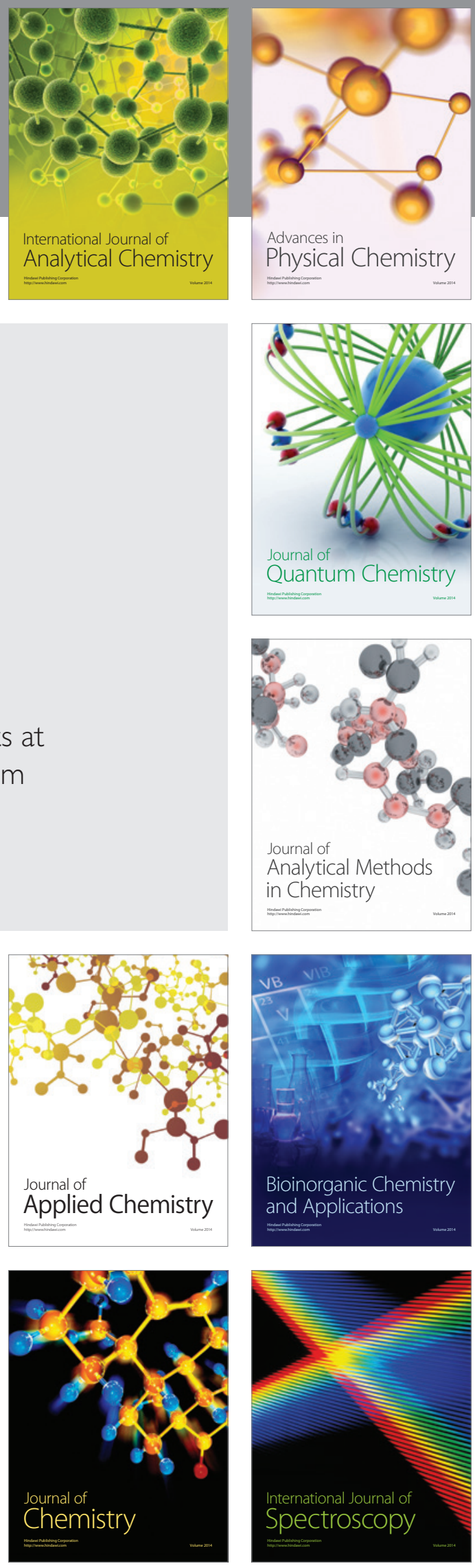